\title{
> Anotações sobre a centralidade do artista na história da arte
}

\author{
> Notes on artist's centrality in the history of art
}

\begin{abstract}
por Ângela Brandão
Professora do Departamento de História da Arte da Universidade Federal de São Paulo. Bolsista Produtividade em Pesquisa CNPq 2. Este artigo também é resultado parcial de pesquisa desenvolvida com apoio FAPESP, Processo 2017/20984-6. E-mail: brandaoangela@hotmail.com. ORCID: 0000-0001-8946-9910.
\end{abstract}

\begin{abstract}
Resumo
Este artigo discute alguns aspectos historiográficos acerca da importância dos artistas, como foco para a construção da narrativa sobre arte no tempo. Nas origens da historiografia da arte, com Giorgio Vasari, as biografias de artistas constituíram o fio condutor do texto. Porém, já se considerava o artista como parte de um sistema do qual faziam parte o ateliê, os mecenas, personagens e contextos sociais que transcendiam à individualidade do artista criador. $O$ texto vasariano foi um modelo a ser seguido e um esquema a ser superado durante os séculos XVII e XVIII, observando os escritos de Bellori ou de Luigi Lanzi. As biografias de artistas foram sendo, portanto, adaptadas aos conceitos de estilo, escola e gênero. A criação do gênero monográfico no final do século XIX, por Carl Justi, permitiu a biografia de um único artista, em lugar do conjunto de vidas. Se, contudo, no início do século XX, pareceu possível construir uma história da arte que ofuscasse o papel do artista, em nome da obra de arte entendida como um objeto em sua pura visibilidade, por autores como Wölfflin; iniciou-se, em contrapartida, uma reconstrução historiográfica na qual o artista voltava a ocupar um papel central na narrativa, porém agora como parte de uma categoria social, em obras como as de Wackernagel, Baxandall ou Warnke.

Palavras-chave: Historiografia da arte. História social da arte. Artista. Biografia
\end{abstract}

\begin{abstract}
This article discusses some historiographical aspects about the importance of artists as a focus for the construction of the narrative on art in time. In the origins of art historiography, with Giorgio Vasari, the biographies of artists constituted the main thread of the text. However, artist was already considered as part of a system that included the studio, the patrons, characters and social contexts that transcended the individuality. Vasarian text was a model to follow and a scheme to overcome during the seventeenth and eighteenth centuries, observing the writings of Bellori or Luigi Lanzi. Biographies of artists were therefore adapted to concepts of style, school and genre.The creation of the monographic genre, by Carl Justi, in the late nineteenth century allowed the biography of a single artist, rather than a set of lives. If, however, at the beginning of the twentieth century, it seemed possible to construct a history of art that overshadowed the role of the artist, in the name of the artwork understood as an object in its pure visibility, by authors such as Wölfflin; in contrast, a historiographical reconstruction began in which the artist returned to occupy a central role in the narrative, as part of a social category, in works such as those ones by Wackernagel, Baxandall or Warnke.
\end{abstract}

Keywords: Historiography of art. Social art history. Artists. Biography 


\section{Introdução}

As anotações que se seguem dedicam-se a compreender certos aspectos da presença do artista na constituição da história da arte como disciplina. A partir da obra de Giorgio Vasari, procuramos traçar algumas linhas sobre a repercussão do modelo das biografias de artistas como eixo central dos estudos históricoartísticos em diferentes épocas. Se alguns autores dos séculos XVII e XVIII procuraram superar, parcialmente, o modelo vasariano, criando conceitos e fórmulas mais gerais para compreender a arte no tempo, como escola, gênero ou estilo, a exemplo de Bellori ou Luigi Lanzi, as vidas dos artistas não deixaram de ser combinadas a tais formulações mais gerais. Em lugar das biografias dos artistas como conjunto de vidas ou adaptadas a um esquema teórico, ao final do século XIX pode-se pensar na escrita da história da arte a partir da biografia de um único artista, por meio do chamado gênero monográfico, que teria sido desenvolvido por primeira vez por Carl Justi.

Embora uma percepção de que fosse possível escrever a história da arte sem depender da biografia dos artistas ou de um artista tenha se afirmado na primeira metade do século XX, a partir da proposição de Wölfflin, vemos surgir escritos em que artistas voltam a ocupar um papel central nos estudos históricoartísticos. Contudo, esses escritos não aparecem no estilo de biografia, mas como categoria social, algo que será observado em estudos como os de Martin Wackernagel, Baxandall e Martin Warnke.

Essas anotações não pretendem ser suficientes, muito menos completas, pois vários aspectos e autores fundamentais foram deixados de lado. No entanto, ainda que de modo fragmentado, procuramos esboçar reflexões a respeito do lugar do artista no tecido da história da arte. 


\section{Vidas}

A história da arte constituiu-se como narrativa com base no modelo biográfico, compreendendo o sujeito artista em sua individualidade. Contudo, mesmo no livro de Giorgio Vasari (1511-1574), embora individualizadas, as biografias dos artistas refletiam uma série de relações sociais: ateliês, mercado de arte, mecenato e formação do artista. $\mathrm{O}$ artífice se afirmava socialmente como cidadão livre, entre os séculos XV e XVI na Itália - no sentido de liberalização das artes e dos fazeres artísticos em relação às corporações de ofício medievais, tais como suas regras e taxas. Neste mesmo processo empreendido por Vasari, como criador da Academia del Disegno ${ }^{1}$, ele próprio construía a primeira narrativa da história da arte, organizada a partir do nome do artista e de sua história pessoal. Afirmava-se socialmente o artista como indivíduo livre e criador, não apenas capaz de dominar uma técnica e dotado de destreza de suas mãos, mas também como intelectual e protagonista da narrativa sobre a arte no tempo.

A construção da centralidade do artista como indivíduo ilustre fora sendo preparada, porém, antes de Vasari, por autores como Filippo Villani, que, em seu livro de 1404, Florença e seus homens ilustres, ao elevar a pintura acima da escrita, louvou artistas florentinos como Cimabue e Giotto. Os escritos da segunda metade do século XV, tais como o tratado De re aedificatoria, de Leon Baptista Alberti² ${ }^{2}$ anunciavam a reinterpretação do papel do arquiteto em direção às artes liberais. Embora a ideia de uma história das artes como agrupamento de biografias interessasse claramente aos humanistas já na primeira metade do século XVI, foi com o livro de Giorgio Vasari, editado em 1550 e 1568, que este projeto se concretizou, com efeito, pela primeira vez. A obra Le vite de' Più Eccellenti Architetti, Pittori e Scultori: Da Cimabue Insino A' Tempi Nostri (editadas em 1550 e 1568), tornou-se o mais célebre livro, por séculos, da história da arte³.

\footnotetext{
${ }^{1}$ Nicolaus Pevsner, Academias de Arte: passado e presente, 2005, p. 105-114.

${ }^{2}$ Leon Baptista Alberti, Da Arte de Construir - Tratado de Arquitetura e Urbanismo, 2012.

${ }^{3}$ Giorgio Vasari, A Vida dos Artistas, 2011.
} 
O projeto historiográfico muito claro e preciso de Vasari ainda hoje baliza, em certo sentido, um modelo narrativo para a história da arte. Especialmente na medida em que se passou a falar na crise, e mesmo no fim da disciplina ${ }^{4}$, segundo Orietta Pinelli, muitos historiadores da arte sentiram-se sem rumo e "atracaram" em Vasari como quem retorna a um porto seguro; porém, não se tratava apenas disso. A escolha da língua vernácula, toscana, por parte de Vasari, em lugar do latim, permitiu-lhe, segundo a autora, uma adaptação ao léxico falado nas oficinas e nos ateliês de artistas, como uma marca de modernidade em sua obra, com a escolha das palavras exatas e da gramática culta, buscando um vocabulário que desse conta dos temas da história da arte, de modalidades e de técnicas artísticas de longa tradição. Uma história baseada em fontes era também uma das questões centrais para Vasari: livros de despesa, receituários, epígrafes, escritos privados, cartas e testemunhos orais e literários. Vários tipos de documentos lhe pareciam dignos de entrar no repertório dos instrumentos da história da arte. Uma vez valorizadas as fontes, como parte de um método histórico e filológico, Vasari propunha, segundo Pinelli, uma autópsia dos fatos, sustentada pela historiografia humanística. Buscava documentos que reconstruíam e comprovavam, encargos e diversos contextos artísticos ${ }^{5}$.

A visão evolutiva da arte apresentada por Vasari, composta por ciclos históricos ou ciclos artísticos, correspondia a um modelo biológico (nascimento, apogeu, decadência e morte). O que se refletia nas biografias estavam organizadas em três partes: infância e juventude (predisposições, ambiente de formação), descrição e avaliação das obras (anedotas para definir a personalidade dos protagonistas, relações, aspirações, pedidos dos comitentes e circunstâncias para realização de cada obra) e anotações sobre o ateliê e os alunos, concluindo o juízo sobre a qualidade da obra. As Vidas se organizavam em três idades ou três eras. A primeira começava, na primeira edição, com o nascimento de Cimabue e fechava com Lorenzo di Bicci - o Trecento, período em que os artistas tomaram,

\footnotetext{
${ }^{4}$ Hans Belting, O Fim da História da Arte, 2012.

${ }^{5}$ Orietta Rossi Pinelli, Storie della Storia dell'Arte, 2014, p. 3 a 11
} 
segundo ele, consciência dos problemas formais e espaciais que seriam resolvidos no Quatrocento. A segunda idade coincidia com a atividade dos mestres do Quatrocento, que deram impulso às artes, iniciando "a regra, ordem, medida, desenho e maneira". Embora não tenham atingido a perfeição, foram úteis para a Terceira Idade, a qual se inicia com Leornardo da Vinci, quando o desenho atinge a perfeição. A Terceira Era se encerrava com Michelangelo na primeira edição, e na segunda, de 1568, com a vida do próprio Vasarí.

Pinelli nos recorda que, na obra de Vasari, os artistas foram tratados como gênios e não mais como artesãos. Ao indicar a influência de um artista sobre o outro, a história da arte começou a ser tecida como uma rede de nomes e obras. $O$ modelo histórico-artístico vasariano estava concentrado na noção da maneira (um termo ambivalente, porém central em sua narrativa), indicando os diferentes traços estilísticos de um artista, uma escola, uma época, e também o repertório das ideias que acompanhavam uma composição figurativa. A maneira, no entanto, poderia também ter conotação negativa por parte do artista, como mera repetição de seu próprio repertório ou como cópia mecânica do estilo de outro ${ }^{7}$.

Segundo Maria Beatrice Failla, o texto vasariano constituiu um modelo, mas, ao mesmo tempo, um sistema a ser superado; uma referência imprescindível, porém que indicava seus próprios limites, já que não poderia se fazer ad nauseam uma continuação infinta de biografias, por meio do esquema das vidas. Como continuar a escrever as Vidas do mesmo modo que Vasari havia feito? Como sistematizar a história da arte para que não se tratasse de um acúmulo sem fim de nomes de artistas? A história da arte trataria de experimentar, nos séculos que se seguiram, novas soluções para combinar a historiografia da arte como narrativa de vidas e uma narrativa do estilo. Em reação ao sistema toscanocêntrico de Vasari, a literatura artística responderá, de

\footnotetext{
${ }^{6}$ Ibidem.

${ }^{7}$ Ibidem, p. 3 a 11.
} 
qualquer forma, com numerosas séries de biografias locais, atualizando e remendando o texto do autor 8 .

O entendimento de como a história da arte se conformou como narrativa de vidas de artistas poderia ser dimensionado igualmente pelo surgimento da autobiografia, que é quando o artista decide escrever sua vida por sua própria mão para usar as palavras de Cellini. Tal como Vasari havia incluído sua autobiografia no conjunto das Vidas na edição de 1568, o manuscrito de Benvenutto Cellini foi redigido entre 1558 e 1562, com a percepção de que sua biografia, embora estivesse presente nas Vite de Vasari, não havia recebido os merecidos louvores. Escreveu: "Todos os homens de toda sorte, que fizeram algo que fosse virtuoso, ou se verdadeiramente que se assemelhe à virtude, deveriam, sendo verdadeiro e do bem, de sua própria mão descrever sua vida9."

\section{Das Vidasa modelos interpretativos}

O sistema historiográfico do século XVII, contudo, propôs novas categorias de subdivisão das obras e dos artistas e novas hierarquias de modelos, alimentado pela difusão da prática de colecionismo. Conceitos como gênero e estilo (ao mesmo tempo em que se configuravam as primeiras ideias sobre escola como categoria estilístico-geográfica da arte) são formulados por meio de reflexão teórica, de observação das experimentações dos artistas e da prática da organização das coleções; além disso, tendiam a superar os limites impostos pelo esquema biográfico vasariano. O pensamento teórico sobre a imitação da natureza e a Ideia passaram, na segunda metade do século XVI, a sustentar uma reflexão sistemática em torno da história da imagem, sobrepondo-se às sequências biográficas ${ }^{10}$.

A primeira metade do século XVII foi marcada não propriamente pela ideia de maneira de Vasari, a partir da qual vão se acumulando identificações de

\footnotetext{
${ }^{8}$ Maria Beatrice Failla, Il governo della vista e il primato dell'invenzione, Op. Cit., 2014, p. 20 a 21.

9 Benvenuto Cellini, Vita. 1901, p. 3.

${ }^{10}$ Maria Beatrice Failla, Op. Cit., 2014, p. 38 a 43.
} 
traços distintivos de artistas e uma nova categoria constituída da intersecção entre a coisa pintada e como se pinta. A historicização do presente se jogou ainda mais uma vez sobre o tema da imitação, e o confronto entre maneiras se tornou uma práxis consolidada na construção historiográfica da disciplina, acolhendo o relativismo de juízo que constituía um dos pontos do sistema vasariano. Começou a formar-se uma cultura historiográfica relacionada a coleções, galerias e Museum - ou pinacotecas. Supunha-se o reconhecimento de uma operação visual na montagem de uma coleção, uma história da arte com base num projeto colecionístico. As quadrarias se tornaram o lugar codificado do confronto entre escolas e maneiras; e o lugar, por excelência, das reflexões historiográficas ${ }^{11}$.

Não obstante um autor como Carlo Ridolfi tenha escrito, em 1648, uma história que mesclava biografias de artistas e narrativas, as Meraviglie dell'arte, como um modelo literário baseado em diálogos, adotando uma postura antibiográfica e antivasariana, no ano anterior, as Vite de Vasari eram reeditadas em Bologna devido à grande demanda pelo livro ${ }^{12}$. Isso demonstra que, embora o século XVII buscasse alternativas ao modelo histórico-artístico vasariano, as Vite continuavam a ser lidas e reeditadas.

Em 1672, Giovan Pietro Bellori publicava Le vite de'pittori, scultori e architetti moderni. O estudo da Antiguidade, o exercício de decifrar e descrever a linguagem visual do Antigo, como modelo descritivo, foi aplicado nas Vite de Bellori, onde a ecfrasi é medida de avaliação da invenção, como parte integrante do sistema teórico para justificar a seleção de biografias. Serão doze na edição de 1672, as vidas de Annibale Carracci, Agostino Carracci, Domenico Fontana, Michelangelo da Caravaggio, Pietro Paolo Rubens, Nicolas Poussin, entre outros. Annibale Carracci assume um papel predominante e se sobrepõe à ideia de progresso, do tempo e das artes. Se, por um lado, Bellori aludia ao modelo evolucionista de Vasari, por outro, refletia o paralelo entre antigos e modernos. Annibale Carracci representava, em seu sistema, o ápice e o progresso em virtude

\footnotetext{
${ }^{11}$ Ibidem.

${ }^{12}$ Maria Beatrice Failla, L'ingano dell'occhio e l'artificio barocco, Op. Cit., 2014, p. 57.
} 
do valor moderno e regenerativo de sua linguagem de síntese. As outras vidas, para Bellori, articulavam-se em torno de Annibale ${ }^{13}$.

Talvez a mais conhecida entre as biografias produzidas por Bellori, no entanto, seja a de Caravaggio, comumente interpretada como uma condenação moral do pintor. Porém, Bellori reconhecia em Caravaggio a redescoberta da natureza por meio de uma verossimelhança das cores, como antídoto para a decadência do maneirismo. A opção de Bellori pelo modelo de biografias resultava, portanto, funcional para constituir uma moldura para a descrição das obras de arte e para caracterizar o exempla virtutis. O paradigma das vidas na história da arte passaria a servir, no fim do século XVII, a uma série de experimentações literárias que recuperavam o sistema vasariano, sobrepondo a ele uma nova historiografia europeia, empenhada nas grandes coletâneas de erudição eclesiástica ${ }^{14}$. A contraposição entre elogio e vida aludia à bifurcação do modelo historiográfico, sendo que a biografia passava a ser, com efeito, um modelo literário aberto. A partir de uma narrativa do estilo, contudo, poder-se-ia refletir sobre uma pintura sem que se conhecesse necessariamente o autor. Por outro lado, atribuir a autoria se tornou uma competência de ouvir o que diziam as obras, depositárias de uma linguagem que apenas o olho poderia decifrar pela leitura do estilo; nascia daí a figura do connoisseur ${ }^{15}$.

Cumpre ascrescentar que Johann Joachim Winckelmann, voltado para o estudo da Arte Antiga, demonstrou pela primeira vez de modo claro e consciente as vantagens de uma história da arte sem artistas. Sua operação historiográfica inovadora abordou o estilo de uma época, o que embora fosse aspiração comum a diversos estudiosos, o fez com capacidade narrativa de síntese absolutamente inédita. Até mesmo o aspecto físico de seus livros, em que não havia muitas páginas, em formato de bolso, com edições elegantes, revelavam a intenção de

\footnotetext{
${ }^{13}$ Ibidem, p. 67-74.

${ }^{14}$ Ibidem.

${ }^{15}$ Chiara Piva, La Repubblica delle Lettere e il dibattito sul metodo storico, Op. Cit., 2014, p. 91 a 142. Jonathan Richardson, An Essay on the Whole Art of Criticism as it Relates to Painting and an Argument in Behalf of the Science of a Connoisseur, 1719.
} 
difundir o conhecimento sobre arte, tornando-a compreensível a um vasto público. Winckelmann percebeu a necessidade de inovar o uso da linguagem da história da arte e se empenhou em reformá-la por meio de neologismos, criticando com ironia escritores precedentes, como Vasari e Bellori ${ }^{16}$.

No final do século XVIII, no entanto, certos autores procurariam, de modo muito geral, criar uma história da pintura e não tanto uma história dos pintores, por assim dizer. Padre Luigi Lanzi (1732-1810), com sua Storia pittorica dell'Italia se propôs a realizar uma vasta síntese da pintura italiana desde o século XIV, até então estudada de modo fragmentado e constituída fundamentalmente de biografias. Lanzi foi inicialmente um estudioso da Antiguidade, um etruscólogo. Sem ser iluminista, por sua fé, nem tampouco um enciclopedista, o hábito de trabalhar sobre objetos anônimos como os da arte etrusca o fez olhar para as obras de arte de todos os tempos por elas mesmas, e não como testemunhos da vida de um artista buscando sua morfologia. Como conservador da Galeria dos Uffizi, de Florença, foi responsável por organizar o acervo e publicar sua primeira descrição em 1782. Ao escrever uma história da pintura italiana, Lanzi adotou o modelo de escolas regionais, da Itália superior e inferior, em lugar das biografias de artistas. A primeira edição de 1792 foi completada por viagens e observação de obras de arte in loco, publicada em dois volumes em 1796 e numa terceira edição em 1809. Lanzi se propôs a definir os estilos e as maneiras dos artistas, das épocas e das escolas; cada escola era dividida em vários períodos, baseando-se na ideia de ciclos de evolução e declínio. No entanto, sua análise pragmática o afastou de teorias, confrontando séries de investigação baseadas, por um lado, nas próprias obras e, por outro, nos documentos. Em certo sentido, Lanzi criava uma geografia da arte capaz de se sobrepor, definitivamente, às biografias ${ }^{17}$.

\footnotetext{
${ }^{16}$ Chiara Piva, Op. Cit., 2014, p. 91 a 142.

${ }^{17}$ Ibidem, p. 142-146.
} 


\section{Vida do artista, no singular}

Ao final do século XIX, podemos ver outro deslocamento importante do modelo de Vasari: as vidas no plural abrem lugar para o estudo da vida de um artista no singular, como completa e suficiente em si mesma para compor uma narrativa autônoma para a história da arte. Nasce o gênero da monografia, que adquire um significado próprio para a historiografia da arte. O livro monográfico teria sido uma criação original de Carl Justi, ao publicar seus estudos sobre Velázquez e Murillo ${ }^{18}$. Não se tratava, no entanto, apenas de isolar a biografia de um artista, mas da inserção da vida do artista na compreensão do contexto mais amplo da época, do ponto de vista de uma história cultural. A vida do artista - e agora de um único pintor, por exemplo - não era apenas uma abordagem do indivíduo, mas observada do ponto de vista social, como, de certa forma, o próprio Vasari já o havia esboçado.

Alguns anos depois da publicação das primeiras monografias em história da arte de Carl Justi, Jacob Burkchardt, historiador da arte suíço que havia dedicado quase toda sua vida ao estudo do Renascimento, escreveu um livro dedicado a Pier Paul Rubens, deixando assim, pouco antes de morrer, aos 78 anos, uma homenagem ao barroco. O livro Recordações de Rubens ${ }^{19}$ não era exatamente uma biografia do pintor; o próprio título recordações revelava a relação íntima do autor com o artista, cuja obra fazia parte de sua memória. $O$ livro representava, de fato, o encontro entre um historiador da arte e um pintor, separados pelo tempo, mas reatados pelo exercício da historiografia da arte. Esta foi, de fato, a única monografia escrita em forma de livro por Burckhardt, que jamais havia dedicado um livro inteiro a um artista, nem mesmo a Rafael. Recordações de Rubens não constituía um gênero literário identificável: biografia, panorama da obra ou então evolução do estilo, mas sim uma espécie de homenagem ao pintor.

\footnotetext{
${ }^{18}$ Carl Justi, Diego Velazquez und sein Jahrhundert, 1888. Carl Justi, Murillo, 1892.

19 Jacob Burckhardt, Rubens, 1967.
} 
Por ser uma recordação, Rubens parecia fazer parte do mundo interior de Burckhardt, que buscava, entretanto, pressupostos concretos e materiais (encomendas, ambiente do ateliê, por exemplo) para compreender a obra. Identificou-a como pintura universal, como arte da contrarreforma e como expressão de um sentido intelectual. Tratava-se, portanto, não de uma simples biografia, mas de uma história da cultura adaptada para Rubens. Ou ainda, segundo Maurer, uma homenagem, através de Rubens, ao mundo barroco. Em suma, Rubens representava, para Burckhardt, a união entre o Norte e o Sul, entre a arte flamenga e a arte italiana, entre a fantasia nórdica e o culto mediterrânico, pela forma e pela narrativa ${ }^{20}$.

\section{A superação do modelo biográfico?}

Aluno de Burckhardt, Heinrich Wölfflin, com suas obras Renascimento e Barroco, de 1888, e Conceitos fundamentais da história da arte, de 1915, sob a influência das ideias da pura visibilidade, inaugurou um novo modelo para os estudos histórico-artísticos, como duplas categorias estéticas. Suas ideias se difundiram por toda a intelectualidade europeia e chegariam a marcar, mais tarde, a historiografia da arte no Brasil. Para Wölfflin, a história da arte era uma narrativa sem artistas, uma história de estilos, de formas, portanto essencialmente antivasariana. A importância de Wölfflin para a história da historiografia da arte correspondia a um certo fim da biografia, por meio de uma escrita baseada em conceitos fundamentais.

Não obstante, desenha-se, no início do século XX, uma história social da arte, cujo foco de observação não se concentra tanto no objeto artístico, mas nos mecanismos sociais de produção artística e na caracterização social e intelectual

\footnotetext{
${ }^{20}$ Emil Maurer e John Haskell, Op.Cit., 1967, p. 17 a 18.
} 
do artista ${ }^{21}$. Por outro caminho, coletivo e social, o artista recuperava um lugar central na narrativa da história da arte.

Martin Wackernagel, aluno de Wölfflin, publicou em 1938 O mundo dos artistas no Renascimento florentino, comitentes, ateliês e mercado de arte ${ }^{22}$. O livro se dividia em três partes: as encomendas ou os encargos; os comitentes (ou encomendantes); o ateliê do artista e o mercado de arte. $\mathrm{O}$ autor tratou especialmente da classe dos artistas: sua força numérica, sua organização corporativa e a articulação das especializações; os ateliês e o método de trabalho (lugares de moradia e de trabalho do artista; organização do trabalho: mestres, ajudantes e aprendizes); o procedimento de produção das esculturas; as técnicas de trabalho dos pintores; a importância do desenho e pintura sobre tela e sobre parede. Tratou, ainda, da formação dos aprendizes e dos assistentes, da gestão dos negócios no ateliê e no mercado de arte, da formação dos preços e das formas de pagamento. Debruçou-se, também, sobre a condição econômica do artista, sua posição social e a consciência de classe dos artistas, assim como do artista como indivíduo - seu círculo de amigos, sua vida e seu trabalho. Escreveu até mesmo sobre a índole do artista, sua mentalidade e o círculo de seus interesses, tratando do tipo do artista na sociedade a ele contemporânea. Já na introdução do livro, Warckenagel explicava seus métodos:

Neste ponto caberia uma declaração de princípio: neste livro, a história da arte não será concebida e tratada nem simplesmente como história do estilo - história da criação de formas e história da visão - nem simplesmente como conectada à história das ideias; será considerada sobretudo enquanto História da completa vida artística (ou inteira vida artística), levando em conta ao máximo possível todos os concomitantes fatores materiais e culturais. Uma vez que nos propusemos este tipo de objetivo, será necessário examinar, enfim, os artistas como grupo no âmbito dos ateliês e do mercado artístico e, em geral, a inteira economia da arte. (...) devemos tentar reconstruir, o quanto possível, a inteira vegetação artística desenvolvida em solo florentino; devemos proceder com o interesse universal, puro e objetivo do botânico, o qual encontra digno de

\footnotetext{
${ }^{21}$ Michael Baxandall, O olhar renascente, pintura e experiência social na Itália da Renascença, 1991. André Chastel, Arte y Humanismo, 1982. Pierre Francastel, Pintura e sociedade, 1990.

${ }^{22}$ Martin Wackernagel, Il Mondo delgi artisti nel Rinascimento Fioretino: commitenti, botteghe e mercato dell'arte, 1994.
} 
observação não só as flores e os frutos perfumados, mas a inteira estrutura da árvore, os simples tufos de ervas e até mesmo as ervas daninhas. ${ }^{23}$

A terceira parte do livro de Wackernagel queria fornecer um documento panorâmico; de um lado, as relações concretas e as circunstâncias do mercado de arte - custo dos materiais, retribuições dos artistas, formas e modos de pagamento - de outro, as condições econômicas e sociais do artista, seu modo de vida e seu estatuto social. A partir desse panorama, pôde ser possível revelar como um mestre emergia do nível médio da vida artística e do artesanato de qualidade, como era organizado o ateliê ou oficina de um artista e como era feita a distribuição de trabalho entre o mestre e os ajudantes.

Entre os pontos tratados por Wackernagel está o grau de especialização do trabalho artístico e de como o status do artista poderia estar ligado, em alguns períodos, ao de outras profissões. Por exemplo, tratou das corporações dos pintores de Florença no século XV, da Companhia de São Lucas, que manteve, segundo ele, um grande número de inscritos ao longo daquela centúria ${ }^{24}$. Outro aspecto observado foi a sobreposição das tarefas e a versatilidade dos artistas, de um lado e de outro, a especialização de tarefas, assim como a permanência do controle de qualidade dos trabalhos realizados pelos artistas por parte das corporações.

O autor observou, como vimos, os ateliês e seu caráter coletivo, a divisão e a organização dos trabalhos artísticos. O mestre supervisionava e controlava os trabalhos, contudo não os realizava integralmente, já que muitas vezes os desenhos preparatórios ficavam a cargo de colaboradores. Wackernagel realizou, portanto, uma análise das mudanças com relação à prática do desenho preparatório, do rascunho, dos esboços e das várias técnicas, assim como analisou a passagem da têmpera ao óleo ${ }^{25}$.

\footnotetext{
${ }^{23}$ Martin Wackernagel, Il Mondo delgi artisti nel Rinascimento Fioretino: commitenti, botteghe e mercato dell'arte, p. 35. Tradução nossa. Grifo nosso.

${ }^{24}$ Ibidem, p.355-356.

${ }^{25}$ Ibidem, p. 356, 360-366.
} 
Em suas palavras:

(...) deve ser sublinhado o quanto as circunstâncias técnicas relativas à criação das pinturas estão estreitamente ligadas à exigência própria da invenção artística e das soluções formais a ela relacionadas. Se olhamos apenas o resultado final, a obra acabada, não conseguimos compreender plenamente a peculiaridade de um mestre nem suas relações com as condições histórico-artísticas que o circundavam. Informações mais diretas as obtemos lá onde, sobre a base dos estudos preliminares conservados, é possível perceber as fases da preparação e da realização da obra. ${ }^{26}$

Wackernagel se dedicou não apenas às técnicas, mas também à análise dos materiais com os quais os artistas trabalhavam. Procurou compreender a formação do artista a partir do desenho e a passagem do aprendiz para o auxiliar ou assistente do artista. Estudou o tempo de realização da obra e cumprimento ou não de contratos, tratando dos preços e pagamentos. Interessou-lhe compreender a posição social do artista e sua consciência de classe. Escreveu:

Considerando seus ganhos, o tipo de trabalho e o teor da vida, o artista, em linha geral, fazia parte socialmente da classe média-alta (...) mas vivia uma dependência contínua, seja pelo trabalho, seja pela vida, de pequenos pagamentos por parte do comitente, o que impedia a possibilidade de uma vida mais livre ${ }^{27}$.

Aproximadamente na metade do século XV, Wackernagel assinala ter havido uma nova consciência despertada por alguns mestres que se rebelavam contra a condição social que os havia mantido por muito tempo num nível baixo da escala social. O livro de Wackernagel tratou ainda da religião dos artistas, sendo que, segundo ele, muitos mantiveram determinada postura estéticoformal com base em sua conduta religiosa. Wackernagel afirmou que nos testamentos de artistas, encontramos muitas expressões de devoção e muitos artistas faziam parte de confrarias religiosas ${ }^{28}$.

O estudo de Wackernagel pode ser considerado, enfim, como um dos primeiros exemplos de uma abrangente história social dos artistas de maneira

\footnotetext{
${ }^{26}$ Ibidem, p. 377.

${ }^{27}$ Ibidem.

${ }^{28}$ Ibidem, p. 382 a 384, 386, 414 a 415.
} 
mais consciente e sistematizada, deslocando o modelo vasariano da biografia individual ou biografias combinadas e também superando o modelo wölffliniano de estudo das obras de arte em sua pura visualidade.

Em 1972, Michael Baxandall publicou o livro O olhar renascente, pintura e experiência social na Itália da Renascença ${ }^{29}$, resultante de uma série de palestras proferidas na Faculdade de História da Universidade de Londres. Seu objetivo era mostrar "como o estilo das pinturas é um material pertinente para a história social". O primeiro capítulo examinava a estrutura do mercado de pinturas no século XV - através de contratos, cartas e registros contábeis. Para ele, uma pintura do século XV era o testemunho de uma relação social: de um lado, o pintor, que realizava o quadro ou supervisionava sua execução; de outro, alguém que o encomendava, fornecia fundos para sua realização. Ambas as partes agiam, segundo ele, conforme instituições e convenções: comerciais, religiosas, preceptivas e sociais.

O cliente pagava pela obra, naquela época como hoje, mas dispunha de seu dinheiro de maneira própria ao século XV, e isso podia influir no caráter da pintura. A relação da qual a pintura é o produto era, entre outras coisas, uma relação comercial, e algumas práticas econômicas daquela época estão muito concretamente materializadas nas pinturas. $O$ dinheiro tem uma importância considerável na história da arte ${ }^{30}$.

Acrescentou ainda: “(...) significa que o pintor se encontrava geralmente exposto a uma relação mais direta com um cliente leigo (...) o pintor se diferenciava do escultor que geralmente trabalhava para grandes organizações comunitárias ${ }^{31 . "}$

Entre as questões abordadas por Baxandall, estava a importância dos contratos para a história da arte. Escreveu: "Há um tipo de documento legal onde estão registrados os elementos essenciais referentes à relação que dava origem a uma pintura, acordos escritos estabelecendo as principais obrigações contratuais de cada parte." Observa, por exemplo, por meio dos contratos, a menção ao ouro,

\footnotetext{
${ }^{29}$ Michael Baxandall, O olhar renascente, pintura e experiência social na Itália da Renascença, 1991.

${ }^{30}$ Ibidem, p. 9.

${ }^{31}$ Ibidem, p. 16.
} 
ao azul ultramarino e à redução de seu uso na pintura no decorrer do século XV. Estabelece, assim, uma espécie de dicotomia entre o uso de materiais nobres e caros em contraposição à habilidade do artista. Baxandall diz: "Uma pessoa pagava um quadro com base nesses dois elementos, a matéria e a habilidade, o material e a mão de obra. (...) Havia uma equivalência nítida e incomum entre os valores teóricos e práticos." E ainda: "O cliente perspicaz dispunha de vários meios para transferir seu dinheiro do ouro para o pincel. Por exemplo, atrás das figuras no seu quadro poderia exigir paisagens em vez de um fundo dourado." Era, segundo Baxandall, um meio seguro de comprar habilidades em vez de investir nos materiais - daí a enorme diferença que se fazia nos ateliês entre o valor do tempo gasto pelo mestre e o valor menor pelo tempo gasto por seus auxiliares ${ }^{32}$.

Este quadro de relações entre os artistas e os comitentes permanece no horizonte da história da arte até o século XXI, com livros como o de Settis, Artistas e Comitentes entre Quatro e Cinquecento ${ }^{33}$, em que trata do jogo das partes: 0 artista na relação com o comitente, questionando-se a própria liberdade do primeiro e transformando agora, em certo sentido, o segundo em protagonista do fenômeno artístico.

O livro de 1996 de Martin Warnke ${ }^{34}$ tratou, por sua vez, do aspecto específico do artista como personagem da Corte e da competição entre os artistas nesse ambiente. Abordou a aparente impossível liberdade do artista diante das encomendas por parte da Corte e, por outro lado, do poder que o artista exercerá para a escolha dos demais cargos ligados às artes - um poder de nomear seus ajudantes. Warnke estudou o sistema de nomeação do artista na Corte, com base em sua fama e reputação, assim como a incorporação da família do artista ao ambiente cortesão. Investigou as formas de remuneração e garantias de sobrevivência, indicando que o artista ali recebia uma remuneração fixa para

\footnotetext{
${ }^{32}$ Ibidem, p. 17, 25 a 28.

${ }^{33}$ Salvatori Settis, Artisti e Comitenti tra Quatro e Cinquecento, 2010.

${ }^{34}$ Martin Warnke, O Artista da Corte. Os antecedentes dos artistas modernos, 2001, p. 65 a 79.
} 
cumprir seu dever de atender às necessidades de seu senhor; no entanto, tal remuneração nem sempre era garantida. Normalmente, segundo ele, o artista vivia no espaço do palácio, embora seu trabalho exigia lugares especiais. Havia também pagamentos em gênero - por exemplo, roupas feitas pela alfaiataria da corte, alimentação, médicos, farmácia e a própria moradia. Nesse contexto, o artista vivia sob a proibição de executar obras para demandas de fora da Corte, sem que houvesse a permissão do mecenas.

Sobre o preço pago pela obra de arte, Warnke escreveu:

Embora as queixas incessantes dos artistas confirmem que, no dia a dia, a prática de pagamentos na corte nem sempre se desenvolvia na atmosfera da liberdade recíproca prometida nos documentos de nomeação e privilégios, é inegável que somente na corte foi possível desenvolver-se uma forma primitiva do fenômeno, tão difícil de compreender, da liberdade de preço da obra de arte. Até agora, a liberação da obra de arte com relação às normas quantitativas das corporações de artesãos vinha sendo atribuída ou a uma mudança na consciência provocada pela teoria da arte ou a um mecanismo burguês de mercado, contra as corporações, sobretudo na Holanda do século XVII (...) $)^{35}$

Outros temas tratados pelo autor foram os episódios em que artistas receberam título de nobreza. Estudou, assim, as tarefas e postos ocupados pelos artistas na Corte, o papel do escultor diante da tarefa dos monumentos públicos, assim como o pintor, sua autoridade e suas funções diplomáticas. O gênero do retrato é abordado por Warnke como o instrumento mais importante da política de arte. Observou, enfim, o artista nessa esfera privada, sua dependência e liberdade em tal ambiente. Após a Revolução Francesa, a oposição entre cultura de Corte e cultura burguesa, para ele, assim como a defesa republicana da liberdade do artista, estigmatizaram o trabalho artístico junto às Cortes, por meio de um discurso burguês. Warnke inverte a ideia de liberdade do artista diante do mercado de arte, se comparada à liberdade que o artista de Corte, para ele, de fato tinha.

A reflexão de Warnke se baseia no princípio teórico-filosófico formulado especialmente entre os séculos XV e XVI, de que o artista é livre porque não

${ }^{35}$ Ibidem, p. 224 a 225. 
exerce trabalho físico. Como arte liberal digna de um homem livre, a pintura ou a escultura deveriam ser exercidas por prazer desinteressado. A arte se origina da virtude, de um dom e do engenho, e a criação da obra se dá na mente do artista. Quem é responsável pela execução braçal da obra é o artesão, que domina a técnica, como uma atividade secundária. A virtude pode ser incentivada e estimulada, mas somente a atividade de produção material pode ser paga. Assim, a partir desse raciocínio, Warnke observa que as belas artes se desvincularam das artes mecânicas no contexto do Renascimento. As corporações se opunham, segundo ele, à situação do artista de Corte, porque este era livre de taxas e obrigações em relação às mesmas corporações ${ }^{36}$.

O livro de Martin Warnke pode ser considerado, assim como o trabalho de Wackernagel, como um estudo fundamental para se perceber a afirmação de uma história da arte que apresenta o artista como personagem central para a compreensão do fenômeno artístico, mas observado de um ponto de vista coletivo e social, e não mais ao molde das biografias.

\section{Conclusão}

A perspectiva histórico-social da arte, à guisa de conclusão, no que se refere ao contexto português, deve muito aos escritos de Vitor Serrão, especialmente ao seu livro O Maneirismo em Portugal e o Estatuto Social dos Pintores Portugueses ${ }^{37}$. $\mathrm{O}$ autor esclareceu suas premissas teóricas no prefácio do livro: "O trabalho, filtrando-se naturalmente, dada a especificidade do tema, nos terrenos de uma História Econômica e Social, de uma Sociologia e análise das mentalidades, de uma História do Direito Civil, etc. não deixa de ser sobretudo um ensaio no domínio da História da Arte ${ }^{38 . "}$

\footnotetext{
${ }^{36}$ Ibidem, p. 65 a 79

${ }^{37}$ Vitor Serrão, História da Arte em Portugal, 2001. Vitor Serrão, O Maneirismo e o Estatuto Social dos Pintores Portugeses, 1983.

38 Vítor Serrão, Op. Cit., 1983, p. 16.
} 
E, mais adiante:

(...) cremos que não existe contradição em considerar simultaneamente a obra como objeto estético e como documento explícito da sua época específica, sendo que ambos os aspectos são complementares e se interligam intimamente. Dentro de uma metodologia sociológico-dialética em que a produção artística, enquanto analisada esteticamente, o é também em conexão com o estudo das ideologias envolventes (ideologia das "zonas" políticas, religiosa, econômica, moral, cultural, etc. em referência um espaço e um tempo determinados) (...) $)^{39}$.

Para concluir essas poucas linhas, podemos dizer que certas tendências da história da arte do século XX confirmaram a construção historiográfica em que o artista voltou a ocupar um papel central em sua organização narrativa, porém não mais na perspectiva das Vidas em conjunto, tampouco como indivíduo isolado, como personagem biografado, mas como parte integrante de uma categoria social e, portanto, parte de um sistema, de um jogo em que atuavam outros setores da sociedade: as Cortes, os comitentes, as corporações e seus artesãos, colecionadores e mecenas. Tal reposicionamento dos artistas, como chave central para a compreensão dos fenômenos artísticos, fez-se sob diferentes abordagens. No entanto, não poderíamos deixar de concordar que, de alguma maneira, a história da arte estaria longe de ter chegado a seu fim e, ao mesmo tempo, ainda oferece tributos a suas origens como disciplina específica.

\section{Referências}

ALBERTI, Leon Baptista. A Arte de Construir. Tratado de Arquitetura e Urbanismo. São Paulo: Hedra, 2012.

BAXANDALL, Michael. O olhar renascente, pintura e experiência social na Itália da Renascença. Rio de Janeiro: Paz e terra, 1991.

BELTING, Hans. O Fim da História da Arte. São Paulo: Cosac \& Naif, 2012.

${ }^{39}$ Ibidem. 
BURCKHARDT, Jacob. Rubens. Pref. Emil Maurer. Trad. e note Anna Bovero. Torino: Einaudi, 1967.

CELLINI, Benvenuto. Vita. Testo critico con introduzione e note storiche.

Firenze: Sansoni, 1901. P. 3 Disponível em

https://archive.org/details/vitadibenvenutoc00cell_0 Acesso em 12 mar. 2019.

CHASTEL, André. Arte y Humanismo. Madrid: Cátedra, 1982.

FAILLA, Maria Beatrice. Il governo della vista e il primato dell'invenzione (1590-1640) in PINELLI, O. R. (org.) Storie della Storia dell'Arte.Torino: Einaudi, 2014.

FAILLA, Maria Beatrice. L'ingano dell'occhio e l'artificio barocco (1640-1680) in PINELLI, O. R. (org.) Storie della Storia dell'Arte.Torino: Einaudi, 2014.

FERNANDES, Cássio da Silva. Martin Wackernagel: o "espaço de vida" dos artistas no Renascimento florentino. Ghrebh, v. 2, p. 16, 2010. Disponível em http://revista.cisc.org.br/ghrebh/ Acesso em 15 de fevereiro de 2019.

FRANCASTEL, Pierre. Pintura e sociedade. São Paulo, Martins Fontes, 1990. JUSTI, Carl. Diego Velazquez und sein Jahrhundert. 2 Bände, Bonn, Cohen, 1888. JUSTI, Carl. Murillo. Leipzig, E. A. Seemann, 1892.

PEVSNER, Niclolaus. Academias de Arte: passado e presente. São Paulo: Companhia das Letras, 2005.

PINELLI, Orietta Rossi. Le arti del disegno. In PINELLI, O. R. (org.) Storie della Storia dell'Arte.Torino: Einaudi, 2014.

PIVA, Chiara. La Repubblica delle Lettere e il dibattito sul metodo storico (16811814). in PINELLI, O. R. (org.) Storie della Storia dell'Arte.Torino: Einaudi, 2014. 
RICHARDSON, Jonhathan. An Essay on the Whole Art of Criticism as it Relates to Painting and an Argument in Behalf of the Science of a Connoisseur. London, 1719. Disponível em:

https://archive.org/details/twodiscoursesia00conggoog/page/n4. Acesso 2 de julho de 2019.

SERRÃO, Vítor. História da Arte em Portugal. Lisboa: Editorial Presença, 2001.

SERRÃO, Vitor. O Maneirismo e o Estatuto Social dos Pintores Portugeses. Lisboa: Imprensa Nacional Casa da Moeda, 1983.

SETTIS, Salvatori. Artisti e Comitenti tra Quatro e Cinquecent. Torino, Einaudi, 2010.

VASARI, Giorgio. A Vida dos Artistas. São Paulo: Martins Fontes, 2011.

WACKERNAGEL, Martim. Il Mondo delgi artisti nel Rinascimento Fioretino: commitenti, botteghe e mercato dell'arte. Roma: Carocci, 1994.

WARNKE, Martin. O Artista da Corte. Os antecedentes dos artistas modernos. São Paulo: Edusp, 2001.

Referência para citação deste artigo BRANDÃO, Ângela. Anotações sobre a centralidade do artista na história da arte. Revista PHILIA | Filosofia, Literatura \& Arte, Porto Alegre, volume 1, número 2, p. 68 - 88, outubro de 2019. 